\title{
Effect of Nanofillers on the Polarization and Depolarization Current Characteristics of New LLDPE-NR Compound for High Voltage Application
}

\author{
N. A. M. Jamail, ${ }^{1,2}$ M. A. M. Piah, ${ }^{2}$ N. A. Muhamad, ${ }^{2}$ Z. Salam, ${ }^{2}$ N. F. Kasri, ${ }^{2}$ \\ R. A. Zainir, ${ }^{2}$ and Q. E. Kamarudin ${ }^{3}$ \\ ${ }^{1}$ Faculty of Electrical and Electronic Engineering, Universiti Tun Hussein Onn Malaysia (UTHM), 86400 Batu Pahat, Johor, Malaysia \\ ${ }^{2}$ Institute of High Voltage \& High Current, Faculty of Electrical Engineering, Universiti Teknologi Malaysia (UTM), \\ 81310 Johor Bahru, Johor, Malaysia \\ ${ }^{3}$ Faculty of Mechanical and Manufacturing Engineering, Universiti Tun Hussein Onn Malaysia (UTHM), \\ 86400 Batu Pahat, Johor, Malaysia
}

Correspondence should be addressed to M. A. M. Piah; fendi@fke.utm.my

Received 1 April 2014; Accepted 5 August 2014; Published 9 September 2014

Academic Editor: Jun Liu

Copyright (C) 2014 N. A. M. Jamail et al. This is an open access article distributed under the Creative Commons Attribution License, which permits unrestricted use, distribution, and reproduction in any medium, provided the original work is properly cited.

Polymeric nanocomposites in which the nanosize fillers are evenly distributed in the polymer material attract attention as an insulating material due to their ability to enhance the materials performance properties of electrical and mechanical. For high voltage (HV) insulation application, one of the targets is to obtain new insulators with improved dielectric properties. This paper presents the outcome of an experimental study to determine the conductivity level of the linear low-density polyethylene(LLDPE-)natural rubber (NR) compound, filled with different amount of $\mathrm{SiO}_{2}$ and $\mathrm{TiO}_{2}$ nanofiller by using the polarization and depolarization current (PDC) measurement technique. linear low-density polyethylene (LLDPE) and natural rubber (NR) with the ratio composition of $80: 20$ are selected as a base polymer. The experiment was conducted to find PDC pattern and conductivity variations of each of the LLDPE-NR/SiO 2 and LLDPE-NR/TiO ${ }_{2}$ samples. The results show that the addition of $\mathrm{SiO}_{2}$ filler exhibited less conductivity compared to $\mathrm{TiO}_{2}$ filler with certain percentage. From the study, it can be concluded that $\mathrm{LLDPE}-\mathrm{NR} / \mathrm{SiO}{ }_{2}$ is a better insulator compared with LLDPE-NR/TiO 2 .

\section{Introduction}

Polyethylene (PE) such as linear low-density polyethylene (LLDPE) is produced via the copolymerization of ethylene with various alpha olefins. They have grown in importance because of the specific properties that can be obtained by varying comonomer content and polymerization condition [1]. Researchers [2] had used epoxy resin as based component. Ibrahim and Dahlan [3] have reported the combination of LLDPE and natural rubber as the most compatible mixes in comparison to other thermoplastic-NR mixes. With further comparison among the PE materials, they found that the LLDPE is most compatible to NR where the rubber particles are dispersed in the continuous phase of thermoplastic components. Researchers [4] found that the compound of
80\% LLDPE and 20\% NR without ATH seems to be the best compound based on the least damage and the lowest normalized degradation index during the mixing process.

With the addition of nanoscale fillers into polymers, robust materials can potentially be produced due to the synergistic effects (cooperating for enhanced effects) arising from the blending process. The fillers added to the polymer-based matrix are just in small quantity, typically less than $10 \mathrm{wt} \%$. All nanocomposites show significantly enhanced thermal stability compared to virgin LLDPE due to the increases of the effective activation energy during degradation process. Furthermore, according to [5] the dynamic mechanical properties of LLDPE/nano-SiO ${ }_{2}$ composites are superior to untreated LLDPE-SiO ${ }_{2}$ composites. Researchers in [6] have performed morphology, electrical, and water treeing 
behaviour testing on LLDPE with the surface treatment of the silica nanoparticles. The composite sample with salinetreated nanoparticles shows improved dielectric properties when compared with the sample with untreated surface nanoparticles. Inorganic nanofillers are frequently used to fabricate polymer nanocomposites.

It is known that the dispersion of a very low ratio of inorganic particles having at least one dimension smaller than $100 \mathrm{~nm}$ can create a network of chemical-physical interactions inside an organic matrix, leading to a dramatic change in the macroscopic properties of the material [7]. This can be translated into the enhancements of some very important characteristics of organic dielectrics, such as the thermal stability and the mechanical strength. Additionally, it exhibits many improved electrical properties, for example, breakdown strength and resistivity of the insulator.

Most previous researches performed morphology studies, breakdown strength test, space charge formation, and dielectric loss test to determine the electrical properties of polymer nanocomposite [8-10]. However, these dielectric measurements are not adequate because they do not reveal information on the polarization current, depolarization current, and the conductivity variation. Without the accurate information of these parameters, it is difficult to determine the cause for the degradation of the insulator.

Condition monitoring technique such as polarization and depolarization current (PDC) measurement has been used to predict the remaining life of the electrical apparatus [11-15]. It is also useful to reduce unscheduled outages, improve maintenance planning, and increase system reliability. PDC analysis also had been done by researcher [15-17] on nanocomposite material to determine the dielectric properties. Analysis of the fundamental dielectric processes has shown that the polarization phenomena are strongly influenced by the morphology and degradation of the polymeric insulation [7]. Therefore, research into the dielectric properties of polymer nanocomposites based on PDC measurement would provide invaluable information to further understand the electrical insulating performance of polymer nanocomposites used in high voltage applications. Hence the objective of this paper is to determine the type of nanofiller that can improve the insulator properties by determining conductivity level of the LLDPE nanocomposite sample.

\section{Experiment}

2.1. Material Preparation. LLDPE was used as the base matrix of the sample. The nanofiller used were silicon oxide $\left(\mathrm{SiO}_{2}\right)$ and titanium oxide $\left(\mathrm{TiO}_{2}\right)$. The LLDPE was mixed with natural rubber (NR) grade SMR CV 60 along with the nanofiller. Detailed specifications of the materials were summarized in Table 1.

2.2. Compounding of Polymer Nanocomposite. The LLDPE sample used in this study is commercially manufactured by Titan Chemical, Malaysia. It has a density of $0.918 \mathrm{~g} / \mathrm{cm}^{3}$ and a melt index of $25 \mathrm{~g} / 10 \mathrm{~min}$. The $\mathrm{SiO}_{2}$ and $\mathrm{TiO}_{2}$ nanofillers were sourced from China. It has an approximately spherical shape with particle size of less than $50 \mathrm{~nm}$. It has specific surface area of about $100 \mathrm{~m}^{2} / \mathrm{g}$. The filler was dried before use. Natural rubber grade SMR CV 60 supplied by Taiko Plantations is mixed and blended with the LLDPE and nanofiller. Polyethylene nanocomposites were prepared by melt mixing at $165^{\circ} \mathrm{C}$ using a Brabender mixer with a chamber size of $50 \mathrm{~cm}^{3}$. The mixer has a high shear force; the screw speed was controlled at $35 \mathrm{rpm}$, and the mixing time was 2 min for each sample.

2.3. Compression Moulding. Test specimens for PDC tests were prepared by using Hydraulic Hot Press Genesis brand manufactured by Wabash MPI USA. The nanocomposites were finally prepared into square shape with the thickness of $3 \mathrm{~mm}$ by hot melt pressing at 1 tone pressure at $170^{\circ} \mathrm{C}$ for $10 \mathrm{~min}$. The cooling process has a significant influence on the morphological features of the sample which may alter the dielectric characteristics. To maintain consistent morphology, the moulded samples were immersed into distilled cool water (quenching) after $10 \mathrm{~min}$ of moulding process. Four types of polyethylene nanocomposite square shape with a dimension of $10 \mathrm{~cm} \times 10 \mathrm{~cm}$ were prepared, with concentrations of nanofiller of $1,3,5$, and $7 \mathrm{wt} \%$, respectively. Table 2 shows the details of the samples prepared.

2.4. Morphological Studies. The nanostructures of the polymer nanocomposites are investigated by using a field emission scanning electron microscope (FESEM), model JEOL JSM-7600F. A $40 \mathrm{~mA}$ sputtering current with 60 seconds of coating time is used during the platinum coating process. The electron gun of FESEM is energised at $10 \mathrm{kV}$ and 3000 times of magnification is used to capture the nanograph of the polymer.

2.5. PDC Measurement. By applying a dc voltage step on the dielectric material the polarization currents measurement is performed. For depolarization current, it is measured by removing the $\mathrm{dc}$ voltage source incorporating with a switch turn onto short circuit at the undertested objects. The dc voltage applied was $1000 \mathrm{~V}$ for about 10,000 seconds for polarization and depolarization time. The voltage and currents were recorded automatically by the control software that was developing in the LabVIEW environment. The PDC measurement principal is shown in Figure 1. PDC testing was done at High Voltage and High Current Laboratory (IVAT), Universiti Teknologi Malaysia (UTM), by using PDC equipment setup as shown in Figure 2.

The estimation of the conductivity for HV insulation under polarization and depolarization test result can be expressed from the PDC value [11-15]. The test object can be a single dielectric material or an arrangement of several dielectric materials in series or in parallel. From the measurements of polarization and depolarization currents, it is possible to estimate the dc conductivity, $\sigma$ of the test object. If the test object is charged for a sufficiently long time, the dc conductivity of the composite dielectric can be expressed as (1) [11-15]. All the obtained data are run and plotted using Matlab. From the plotted figures, the trend and pattern of 
TABLE 1: Detailed properties of materials.

\begin{tabular}{lcccc}
\hline Material & LLDPE & NR-SMR CV 60 & Silicon oxide $\left(\mathrm{SiO}_{2}\right)$ & Titanium oxide $\left(\mathrm{TiO}_{2}\right)$ \\
\hline Manufacturer & Titan Chemical & Taiko Plantation & Hongwu Nanometer, China & Hongwu Nanometer, China \\
\hline & & Melting temperature: $160^{\circ} \mathrm{C}$ & Form: hydrophilic solid & Form: hydrophobic solid \\
Properties & Density of $0.918 \mathrm{~g} / \mathrm{cm}^{3}$ & Nitrogen: $0.36 \% \mathrm{wt}$ & powder & rutile \\
& Melt index of $25 \mathrm{~g} / 10 \mathrm{~min}$ & Mooney viscosity: 64 & Color: white & Color: white \\
& & Dirt content: $0.02 \%$ & Size: $20-30 \mathrm{~nm}$ & Size: $<50 \mathrm{~nm}$ \\
& & & & \\
& & &
\end{tabular}

TABLE 2: Compound formulations and designation.

\begin{tabular}{|c|c|c|c|c|}
\hline \multirow{2}{*}{ Test sample } & \multicolumn{3}{|c|}{ Constituent composition wt $\%$} & \multirow{2}{*}{ Designation } \\
\hline & LLDPE & Natural rubber (SMR CV 60) & Nanofiller & \\
\hline LLDPE + natural rubber & 80 & 20 & 0 & A0 \\
\hline \multirow{4}{*}{$\mathrm{LLDPE}+$ natural rubber $+\mathrm{SiO}_{2}$} & 80 & 20 & 1 & A1 \\
\hline & 80 & 20 & 3 & A3 \\
\hline & 80 & 20 & 5 & A5 \\
\hline & 80 & 20 & 7 & A7 \\
\hline \multirow{4}{*}{$\mathrm{LLDPE}+$ natural rubber $+\mathrm{TiO}_{2}$} & 80 & 20 & 1 & B1 \\
\hline & 80 & 20 & 3 & B3 \\
\hline & 80 & 20 & 5 & B5 \\
\hline & 80 & 20 & 7 & B7 \\
\hline
\end{tabular}

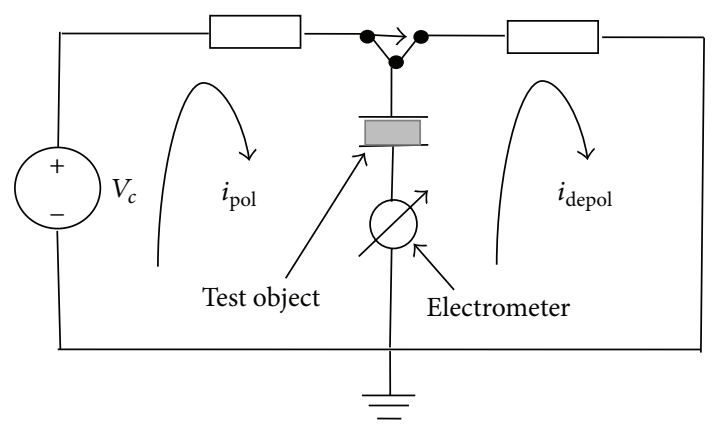

FIGURE 1: PDC measurement concept.

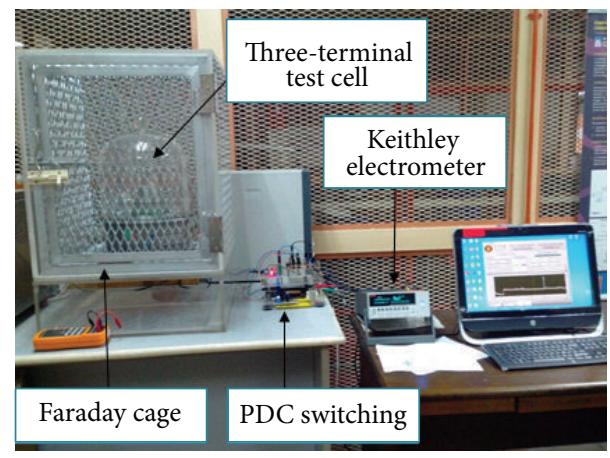

FIGURE 2: PDC measurement setup.

the conductivity will be determined; either an upward or a downward trend is expected

$$
\sigma \approx \frac{\varepsilon_{o}}{C_{o} U_{o}}\left[i_{p}(t)-i_{d}(t)\right]
$$

where $\sigma$ is the composite conductivity, $\varepsilon_{o}$ is the relative permittivity, $C_{o}$ is the geometric capacitance, $U_{o}$ is the step voltage, $i_{d}(t)$ is the depolarization current, and $i_{p}(t)$ is the polarization current.

\section{Results and Analysis}

3.1. Morphology Analysis. Figures 3 and 4 show result of FESEM images for each sample of LLDPE-NR/SiO ${ }_{2}$ and LLDPE-NR/TiO 2 . For the compounds filled with low and moderate content of nanofiller, the basic components in the compound are homogeneously dispersed and only small agglomeration of the fillers occurs as shown in Figures 3(a), 3(b), 4(a), and 4(b). This shows that the interaction between fillers and the polymer matrix is strong. Figures $3(\mathrm{~d})$ and $4(\mathrm{~d})$ have shown that more composition wt $\%$ of nanofiller tends to agglomerate each other. For higher content of nanofillers, the material compounding becomes rougher due to difficulty in dispersing nanofiller uniformly in the compound. In the LLDPE-NR/SiO ${ }_{2}$ and LLDPE-NR/TiO ${ }_{2}$ composites, there are some particles contacts in agglomerates that contribute to a larger number of $\mathrm{SiO}_{2}$ and $\mathrm{TiO}_{2}$ particles. Agglomerates in both composite samples, those observed in the sample are clearly larger size for higher wt $\%$ of nanofiller. The silanol groups at the surface of silica nanoparticles tend to form hydrogen bonds which can contribute in a strong tendency toward agglomeration in the polymer matrix.

The interaction between the matrix and the fillers is related to the chemical properties of the filler surface and the interfacial area between the matrix and the fillers. The stronger the interaction and the larger the interfacial area, the greater the volume of the bound part. Because the molecules 


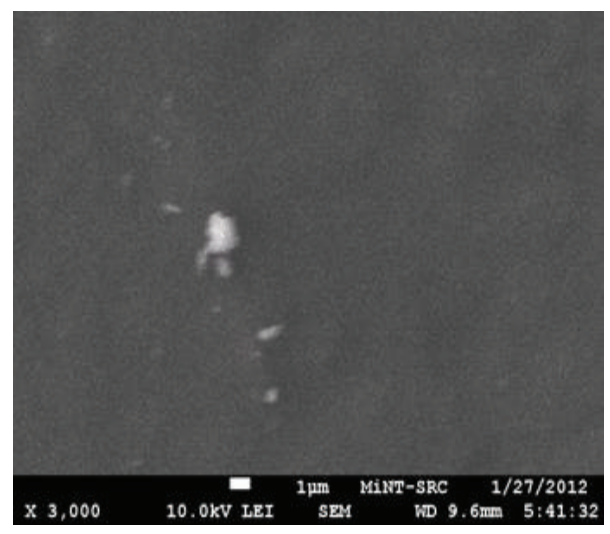

(a)

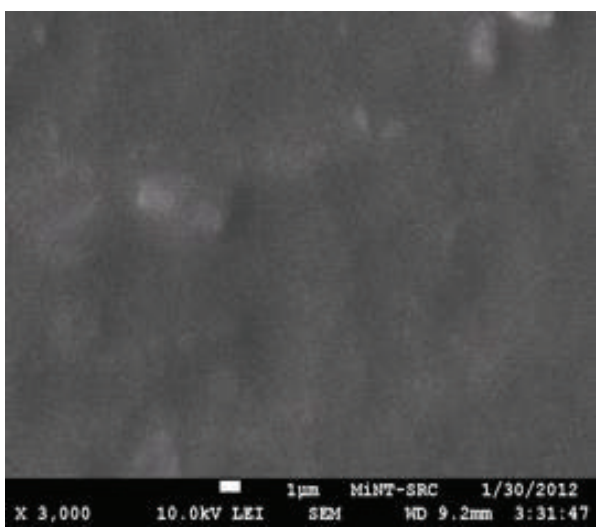

(c)

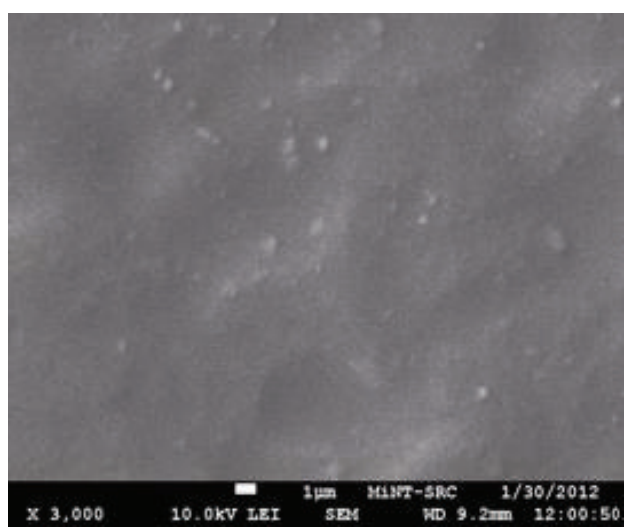

(b)

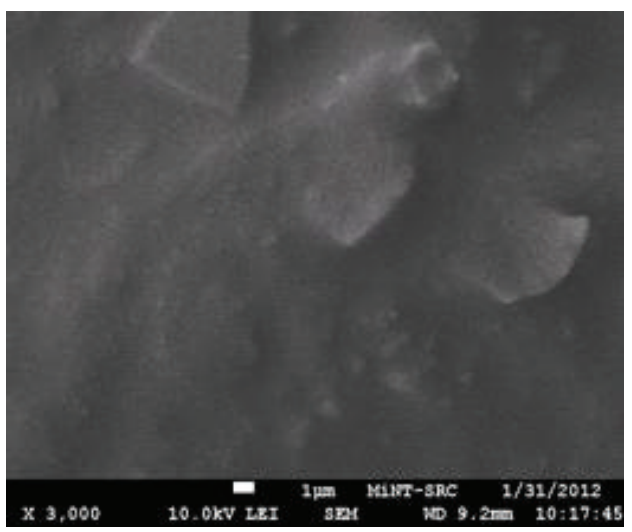

(d)

FIgURE 3: FESEM images of the samples. (a) Sample A1, (b) sample A3, (c) sample A5, and (d) sample A7.

of the bound part are restricted to the surface of the fillers, the molecular motion is greatly limited [5].

3.2. Polarization and Depolarization Current Analysis. The results for polarization and depolarization currents measured for sample in group A are shown in Figures 5 and 6. Based on the graphs that were plotted, sample A5 has the lowest value of polarization and depolarization current. This shows that sample A5 has a lower level of conductivity as compared to the other samples. Sample A5 which has $5 \mathrm{wt} \%$ of $\mathrm{SiO}_{2}$ shows the lowest polarization current recorded and this can be related to higher resistivity. The study shows that $5 \mathrm{wt} \%$ of $\mathrm{SiO}_{2}$ will produce the optimum composition for LLDPE-NR polymer in order to increase the resistivity of the material. The interaction between the matrix and the fillers depends on the chemical properties of the filler surface and the interfacial area between the matrix and the fillers. The empty zone in the material had been filled with nanofiller. $\mathrm{SiO}_{2}$ nanofillers have dielectric properties due to its lower conductivity value [17].

Sample A7 shows the highest polarization current compared with others in group A. Agglomeration of nanofillers in the composite sample tends to increase the moving charges that can contribute to higher polarization current and conductivity. Dielectric permittivity of micrometric agglomerate was higher than that of particles material. There exist hydroxyl group in $\mathrm{SiO}_{2}$ nanofillers and molecularly absorbed water on the surface of nanofillers which can introduce more charge carriers and consequently cause higher polarization current.

The results for polarization and depolarization currents measured for samples in group B are shown in Figures 7 and 8 . Based on the current patterns that were plotted, it is shown that the value of current increased significantly when the $\mathrm{TiO}_{2}$ nanofiller was increased from $1 \mathrm{wt} \%$ to $5 \mathrm{wt} \%$. These results also comply with the fact that the $\mathrm{TiO}_{2}$ nanofiller is a reactive semiconductor. Therefore, it is not suitable to be used as high voltage insulating materials due to the higher PDC recorded.

3.3. Conductivity Variation Analysis. Polarization and depolarization current measurement allows for an estimation to be made on the condition (moisture and ageing) of the insulation with different conductivities. From (1), it proves that conductivity of the insulation is influenced by polarization and depolarization current values.

Conductivity variations for LLDPE-NR/SiO 2 samples for different amount of nanofiller are shown in Figure 9. Based on the figure, when the percentage of $\mathrm{SiO}_{2}$ nanofiller increased from $1 \mathrm{wt} \%$ to $5 \mathrm{wt} \%$, the conductivity of LLDPE-NR/SiO is decreased. When the percentage of nanofiller content is 


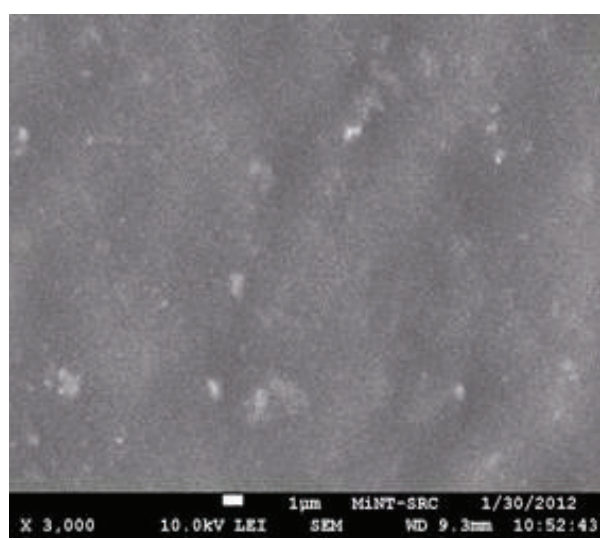

(a)

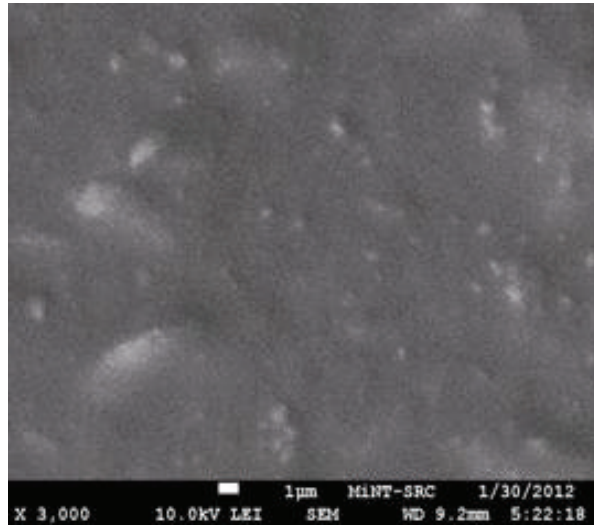

(c)

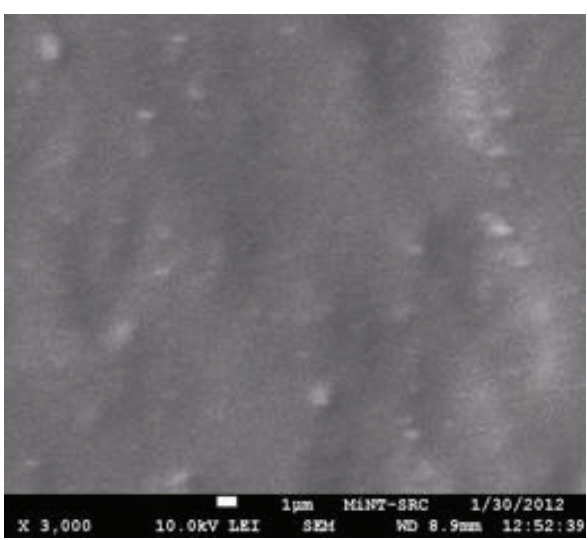

(b)

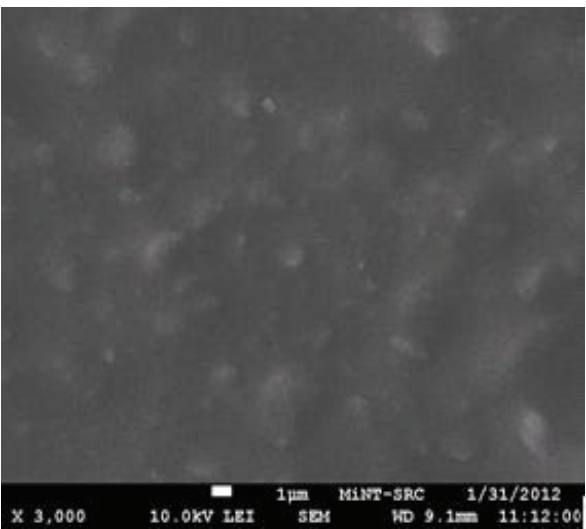

(d)

Figure 4: FESEM images of the samples. (a) Sample B1, (b) sample B3, (c) sample B5, and (d) sample B7.

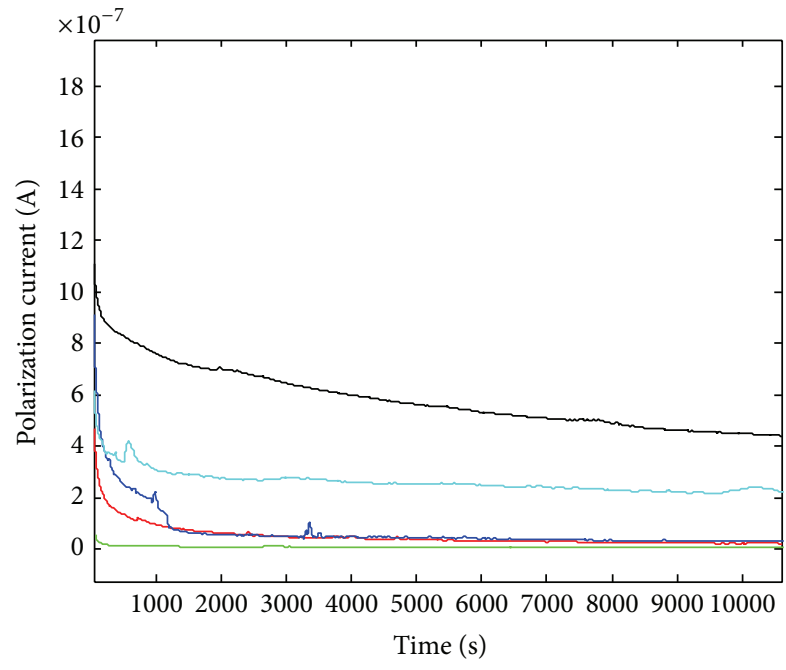

$-\mathrm{A} 0$

- A5

$-\mathrm{A} 7$

Figure 5: Polarization current values for samples A0, A1, A3, A5, and A7.

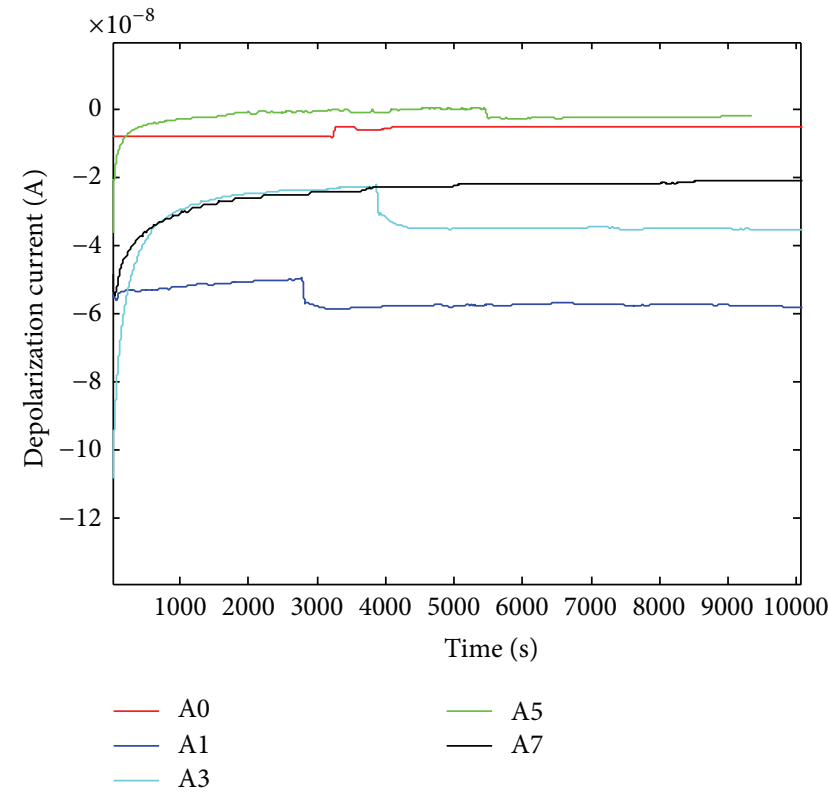

FIgURE 6: Depolarization current values for samples A0, A1, A3, A5, and A7. 


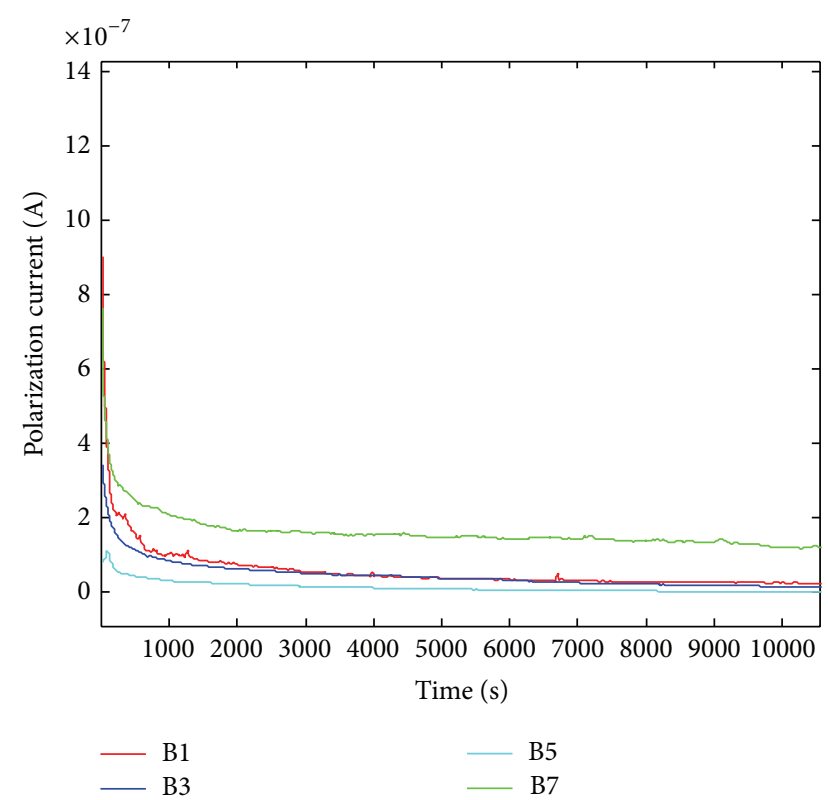

FIGURE 7: Polarization current values for samples B1, B3, B5, and B7.

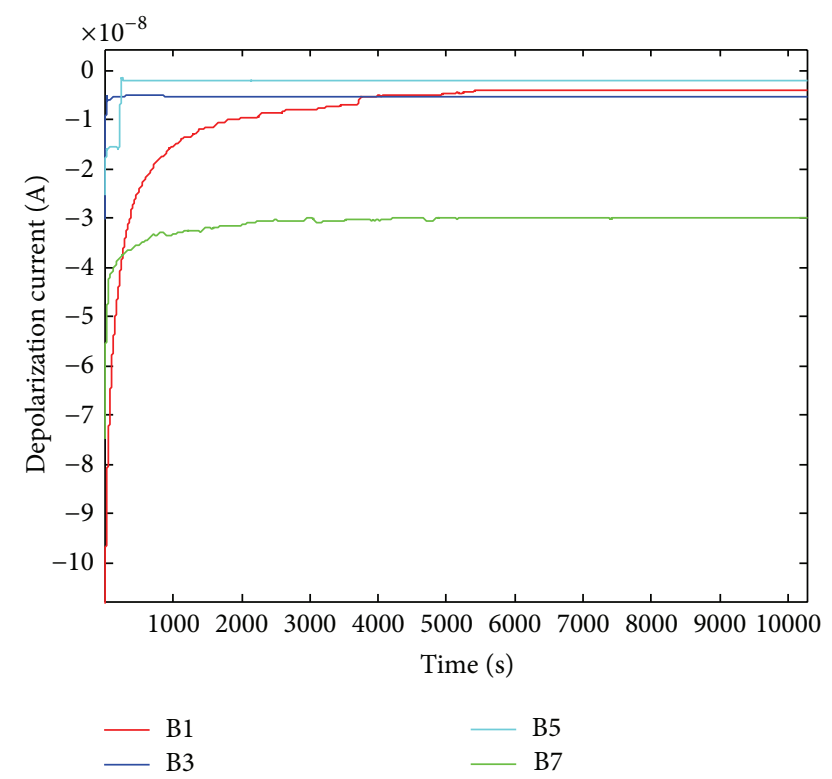

FIGURE 8: Depolarization current values for samples B1, B3, B5, and B7.

further increased to $7 \mathrm{wt} \%$, the conductivity increases and is higher than the sample with $3 \mathrm{wt} \%$ and $5 \mathrm{wt} \%$. The sample of $5 \mathrm{wt} \% \mathrm{SiO}_{2}$ nanofiller is found to be the best compound because it has the lowest conductivity compared to the others from the same group. Nanofillers will fill up the empty bond of the composite matrix in the composite sample.

The higher value of conductivity of A7 as compared to A5 indicates that the $\mathrm{SiO}_{2}$ nanofiller of more than $5 \mathrm{wt} \%$ has reversed the improvement on the dielectric properties of LLDPE. This is because the filler will agglomerate in both composite samples. Those observed in the sample are

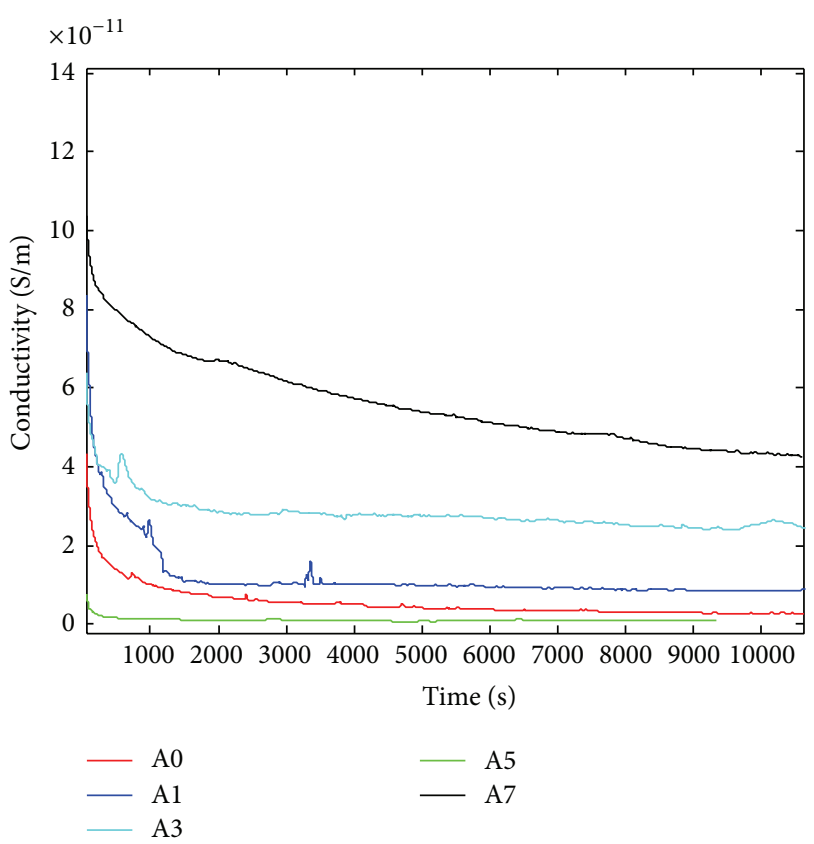

FIGURE 9: Conductivity variations for sample LLDPE-NR/SiO $\mathrm{S}_{2}$ at different amount of nanofiller.

clearly larger size of filler for higher wt $\%$ of nanofiller. Agglomeration of nanofillers in the composite sample tends to increase the moving charges that can contribute to higher polarization current and conductivity. More improvement can be done by addition of $\mathrm{SiO}_{2} 5 \mathrm{wt} \%$ as filler for dielectric properties and lower conductivity level as compared to other composition. The properties of $\mathrm{SiO}_{2}$ nanofiller as dielectric filler tend to improve the dielectric properties as a good insulator.

Figure 10 shows the conductivity variations of LLDPE$\mathrm{NR} / \mathrm{TiO}_{2}$. The figure shows that the conductivity level is increased when $\mathrm{TiO}_{2}$ nanofiller increases from $1 \mathrm{wt} \%$ to $5 \mathrm{wt} \%$. Sample B5 has a higher conductivity value as compared to the conductivity value of sample A5. It can be summarized that the conductivity of the samples will be different when different percentage (wt $\%$ ) of $\mathrm{TiO}_{2}$ nanofiller is used. Since this nanofiller is semiconductor filler, it is not very suitable to be used as an insulator due to the nature of its properties. $\mathrm{SiO}_{2}$ nanofiller had given better properties in terms of conductivity for $\mathrm{HV}$ insulation application as compared with $\mathrm{TiO}_{2}$ nanofiller.

\section{Conclusions}

Morphology and conductivity of LLDPE-NR/SiO ${ }_{2}$ and LLDPE-NR/TiO 2 samples have been conducted and studied in this paper. Morphology results show that, for the LLDPE$\mathrm{NR} / \mathrm{SiO}_{2}$ and LLDPE-NR/TiO ${ }_{2}$ composites, there are some particles contacts in agglomerates that produced a larger number of $\mathrm{SiO}_{2}$ and $\mathrm{TiO}_{2}$ particles, while observations on agglomeration on both composite samples show that they are larger in size when higher percentage (wt\%) of nanofiller is used. 


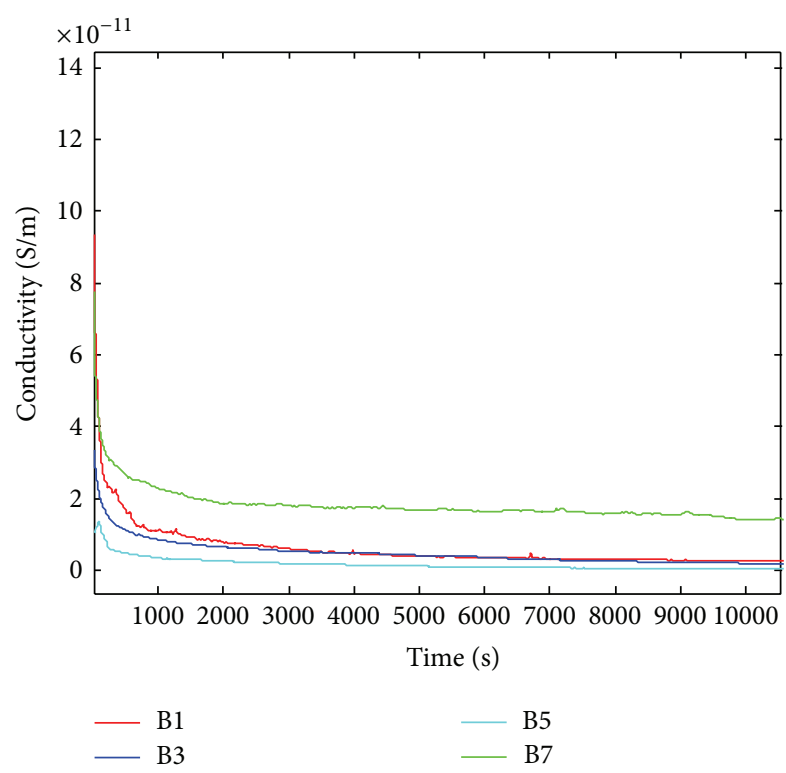

FIGURE 10: Conductivity variations for sample LLDPE-NR/TiO ${ }_{2}$ at different amount of nanofiller.

Based on the PDC measurement results, it was found that adding $\mathrm{SiO}_{2}$ as nanofiller at certain percentage will improve the dielectric properties of LLDPE. However, additional $\mathrm{TiO}_{2}$ nanofiller will make it worse. The LLDPE-NR/SiO 2 at $5 \mathrm{wt} \%$ has been found to be the best composition for $\mathrm{HV}$ insulation in terms of the lowest polarization and depolarization current values as well as the lowest conductivity level. Furthermore, the trends of the conductivity variation were found to be dependent on the polarization and depolarization currents values. These trends can be used to evaluate the condition of the HV insulation.

\section{Conflict of Interests}

The authors declare that there is no conflict of interests regarding the publication of this paper.

\section{Acknowledgments}

The authors gratefully acknowledge the Universiti Tun Hussein Onn Malaysia (UTHM), Universiti Teknologi Malaysia (UTM), Malaysia Ministry of Education (MOE), and Ministry of Science, Technology and Innovation (MOSTI), under Grant vote nos. GUP:08H65 and 04H67, ERGS:4L133, FRGS:4F515, and eSCIENCE:4S101, for financial support, TNB Research Sdn Bhd for equipment support, and Taiko Plantation Sdn Bhd as a supplier of natural rubber.

\section{References}

[1] W. Owpradit and B. Jongsomjit, "A comparative study on synthesis of $\mathrm{LLDPE} / \mathrm{TiO}_{2}$ nanocomposites using different $\mathrm{TiO}_{2}$ by in situ polymerization with zirconocene/dMMAO catalyst," Materials Chemistry and Physics, vol. 112, no. 3, pp. 954-961, 2008.
[2] Y. R. Lee, S. C. Kim, H. Lee et al., "Graphite oxides as effective fire retardants of epoxy resin," Macromolecular Research, vol. 19, no. 1, pp. 66-71, 2011.

[3] A. Ibrahim and M. Dahlan, "Thermoplastic natural rubber blends," Progress in Polymer Science, vol. 23, no. 4, pp. 665-706, 1998.

[4] M. A. M. Piah, A. Darus, and A. Hassan, "Electrical tracking performance of LLDPE-natural rubber blends by employing combination of leakage current level and rate of carbon track propagation," IEEE Transactions on Dielectrics and Electrical Insulation, vol. 12, no. 6, pp. 1259-1265, 2005.

[5] Y. Huang, S. Jiang, L. Wu, and Y. Hua, "Characterization of $\mathrm{LLDPE} /$ nano- $\mathrm{SiO}_{2}$ composites by solid-state dynamic mechanical spectroscopy," Polymer Testing, vol. 23, pp. 9-15, 2004.

[6] X. Huang, F. Liu, and P. Jiang, "Effect of nanoparticle surface treatment on morphology, electrical and water treeing behavior of LLDPE composites," IEEE Transactions on Dielectrics and Electrical Insulation, vol. 17, no. 6, pp. 1697-1704, 2010.

[7] A. Sami, E. David, and M. Frechette, "Electrical insulation and dielectric phenomena," in Proceedings of the IEEE Conference on Electrical Insulation and Dielectric Phenomena (CEIDP '09), pp. 689-692, 2009.

[8] T. Andritsch, R. Kochetov, B. Lennon, P. H. F. Morshuis, and J. J. Smit, "Space charge behavior of magnesium oxide filled epoxy nanocomposites at different temperatures and electric field strengths," in Proceedings of the 30th Electrical Insulation Conference (EIC '11), pp. 136-140, June 2011.

[9] D. Fabiani, G. C. Montanari, and L. Testa, "Effect of aspect ratio and water contamination on the electric properties of nanostructured insulating materials," IEEE Transactions on Dielectrics and Electrical Insulation, vol. 17, no. 1, pp. 221-230, 2010.

[10] S. Masuda, S. Okuzumi, R. Kurniant et al., in Proceedings of the Annual Report Conference on Electrical Insulation and Dielectric Phenomena (CEIDP '07), pp. 290-293, 2007.

[11] T. K. Saha, M. K. Pradhan, and J. H. Yew, "Optimal time selection for the polarisation and depolarisation current measurement for power transformer insulation diagnosis," in Proceedings of the IEEE Power Engineering Society General Meeting (PES '07), pp. 1-7, June 2007.

[12] T. K. Saha and P. Purkait, "Investigation of polarization and depolarization current measurements for the assessment of oilpaper insulation of aged transformers," IEEE Transactions on Dielectrics and Electrical Insulation, vol. 11, no. 1, pp. 144-154, 2004.

[13] N. A. Muhamad, B. T. Phung, T. R. Blackburn, and K. X. Lai, in Proceedings of the Australasian Universities Power Engineering Conference (AUPEC '09), pp. 1-6, 2009.

[14] C. Ekanayake, T. K. Saha, H. Ma, and D. Allan, in Proceedings of the IEEE Power and Energy Society General Meeting, pp. 1-8, 2010.

[15] T. K. Saha and P. Purkait, "Investigation of an expert system for the condition assessment of transformer insulation based on dielectric response measurements," IEEE Transactions on Power Delivery, vol. 19, no. 3, pp. 1127-1134, 2004.

[16] M. Frechette, F. Guo, M. Heid et al., "Dielectric response of polyethylene modified with nanosilica," in Proceedings of the IEEE Electrical Insulation Conference (EIC '13), pp. 276-280, Ottawa, Canada, June 2013.

[17] I. Preda, J. Castellon, S. Agnel et al., in Proceedings of the IEEE International Conference on Solid Dielectrics (ICSD '13), pp. 1060-1063, 2013. 

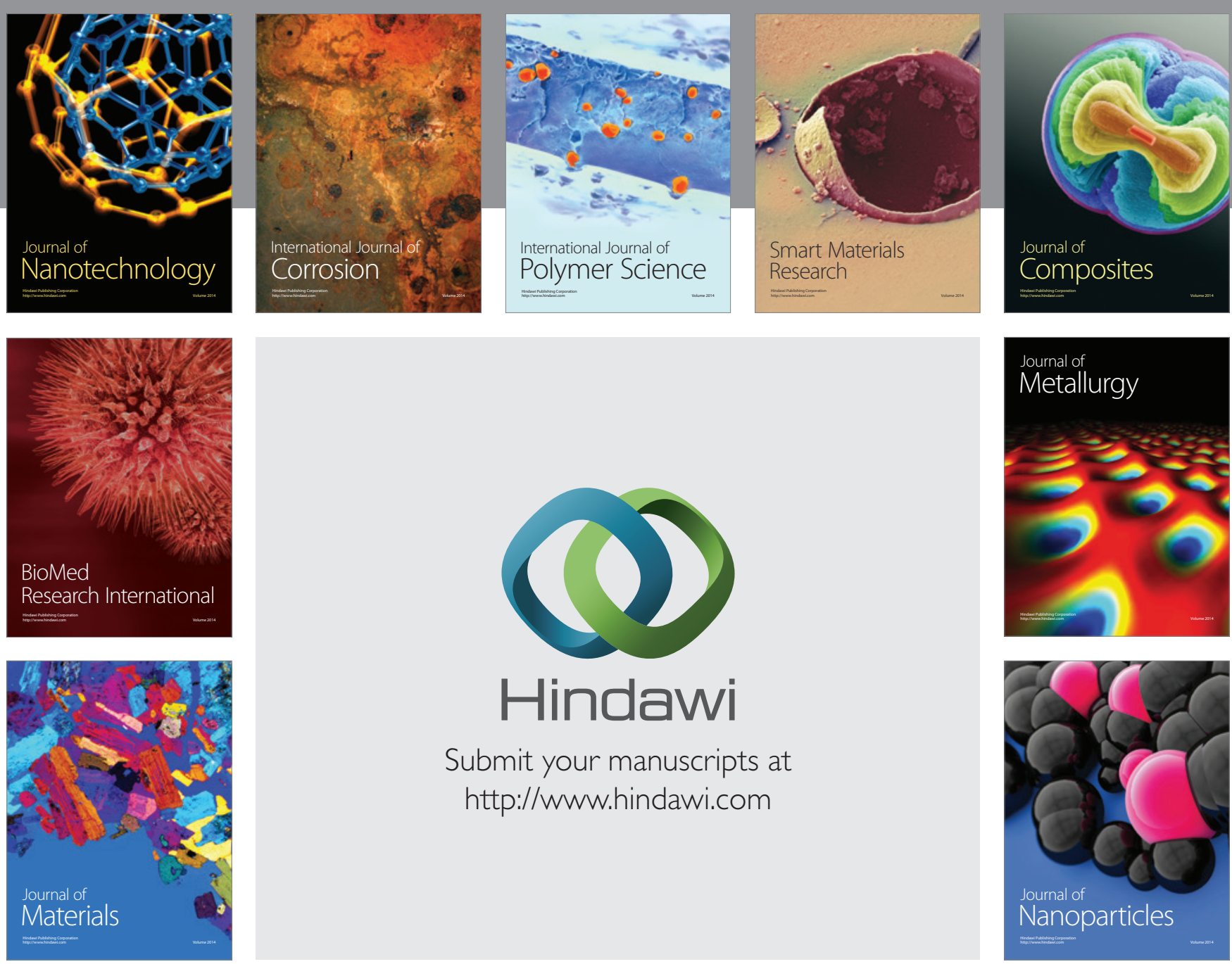

Submit your manuscripts at http://www.hindawi.com
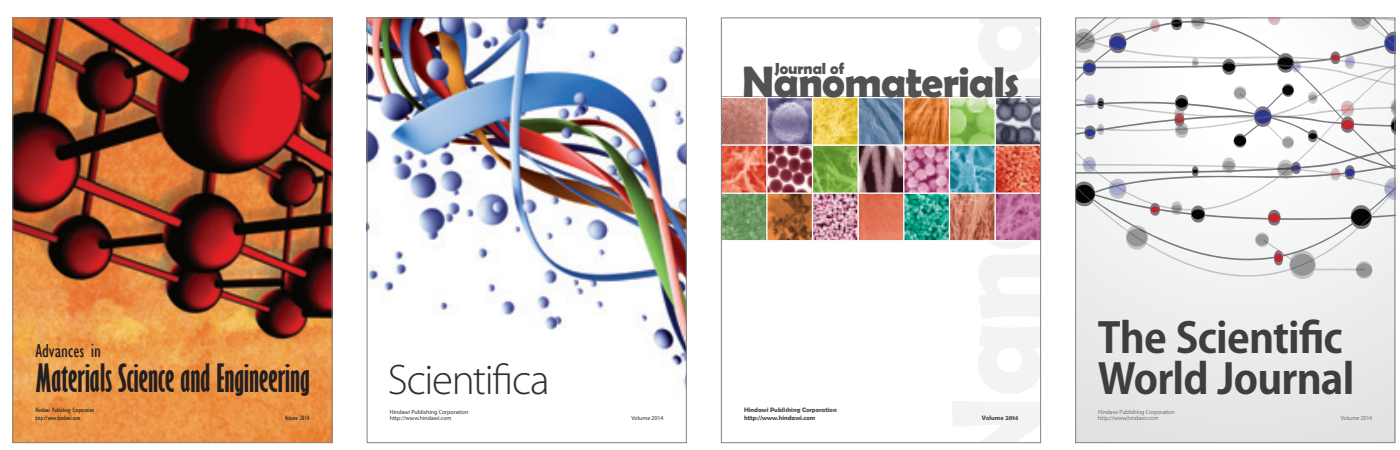

\section{The Scientific World Journal}
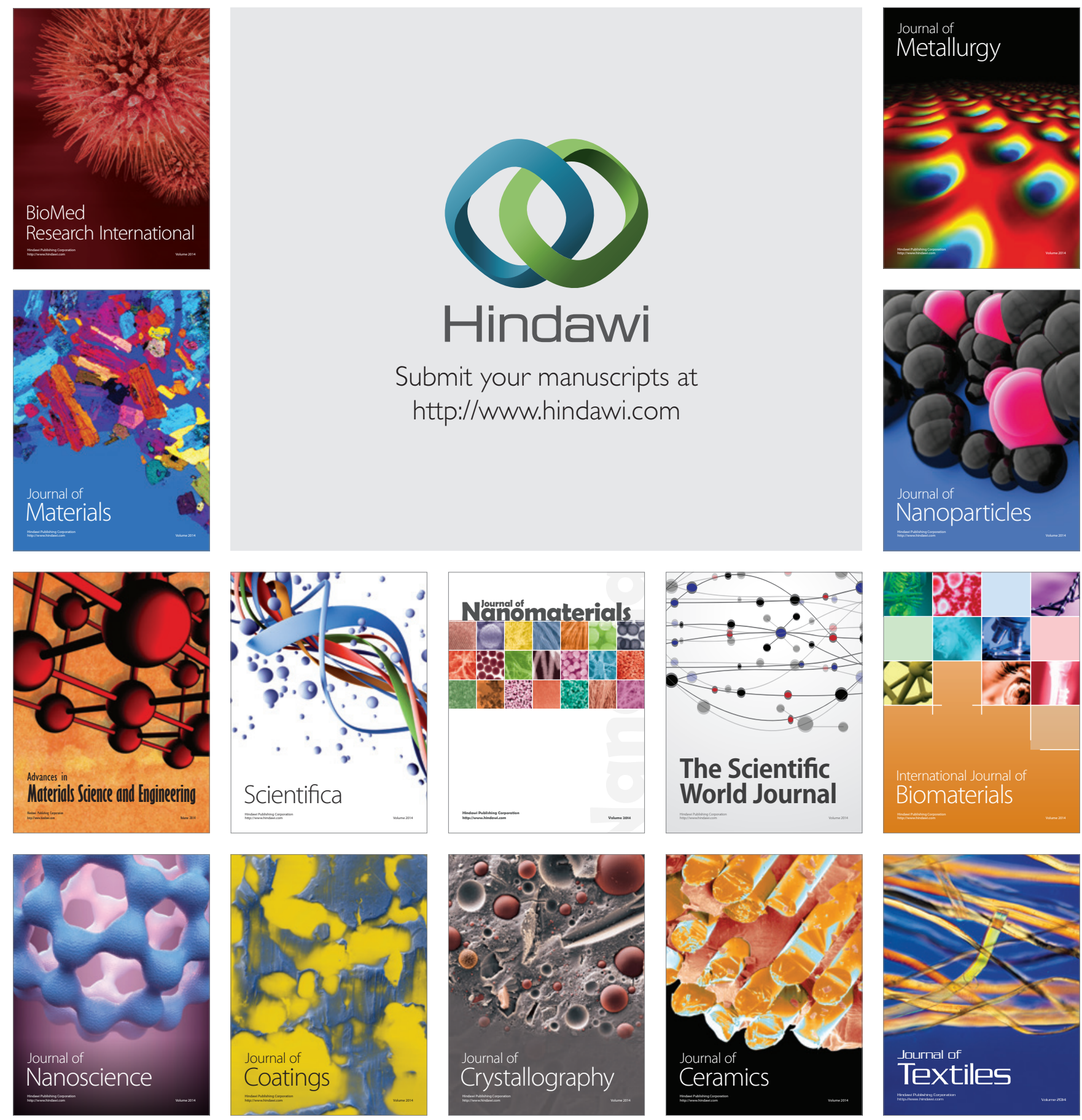